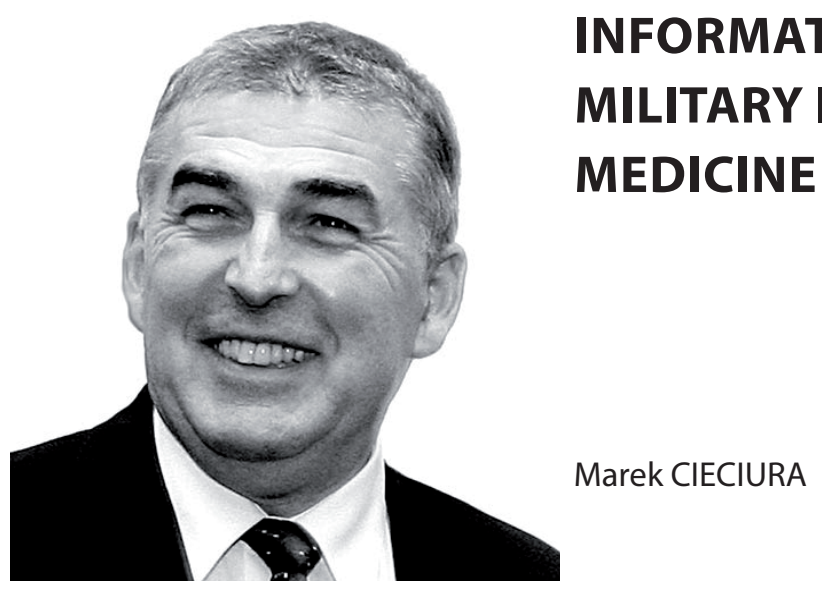

\title{
INFORMATION TECHNOLOGY AT THE MILITARY INSTITUTE OF AVIATION MEDICINE FROM 1980 TO 1995
}

Source of support: Own sources

Author's address: M. Cieciura, Warsaw, Poland, e-mail: cieciura.marek@gmail.com

Abstract: Author, retired colonel, MD Engineer, in the years 1980-1995 head of the Department of Medical Information Technology at the Military Institute of Aviation Medicine and the Chief Specialist of the Military Health Service in the field of Medical Information Technology, pre-sents the designed and implemented IT systems in Polish aviation medicine as well as the effects and plans of further computerization.

Keywords: medical information technology, implementation effects of medical information technology at the Military Institute of Aviation Technology 


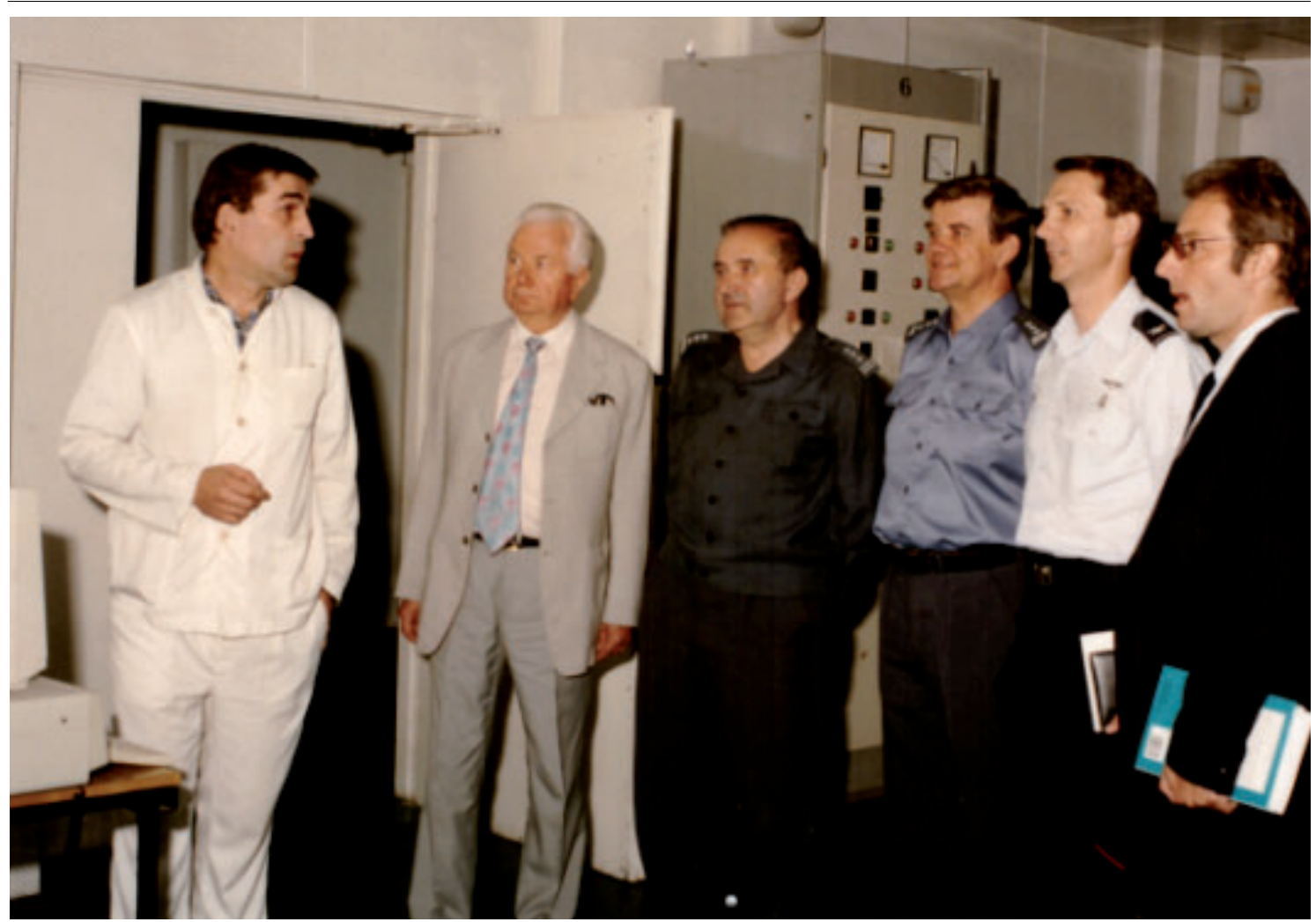

Fig.1. Presentation of the MIAM's certification system (from the left: author, colonel doc. Zbigniew Sarol, colonel prof. Stanisław Barański - Commandant of MIAM, colonel prof. Krzysztof Kwarecki - Deputy Commandant of MIAM, delegate of the American Army, and lieutenant colonel dr. Jerzy Achimowicz).

The Military Institute of Aviation Medicine (MIAM) is a military health care institution which started to use IT methods and means as early as in the 1960s. Natural changes in the scope of methods used and in the use of increasingly modern computer equipment occurred during this period.

At the beginning of the 1980s, the main computer at MIAM was the Odra 1304 computer. It was replaced by one of the first in the Polish Army two SM-4 type minicomputers, whose terminals were installed in various units of the Institute. Microcomputers of IBM PC type, which are usually integral parts of examination support systems, were gradually put into operation. Gradually, these microcomputers were coupled with central minicomputers.

\section{SYSTEMS SUPPORTING CERTIFICATION ACTIVITY}

First of all, the systems supporting the certification process of the Central Military Aviation and Medical Commission (CMAMC) in the scope of military and civilian flying personnel were designed. They were developed in a modular structure, which made it easier to make the required modifications, changes and additions.
In CMAMC systems, the results of daytime certification were entered on the basis of a medical examination card and additional test results from the terminals installed at the CMAMC receptions. Apart from the tests carried out by CMAMC, information on hospital stays, ailments diagnosed there, possible referrals for further treatment in sanatoria, and on exemptions from work activities granted was also recorded. Every day, immediately after the data entry was completed, the daily report was prepared and the databases were updated. The systems significantly relieved the CMAMC units of the burden of developing timeconsuming and laborious reports on health of military and civilian flying personnel.

The collected results of specialist and additional examinations enabled current analysis of health condition and forecasting of drop out rate of flying personnel. The obtained conclusions were used in prevention, human resources and training activities, as well as in the course of certification and scientific research activities MIAM'.

1 The author of the article and his team were awarded the Second Degree Team Prize in Military Medicine on 12 October 1988 by the Minister of National Defense for the development of systems supporting the certification and medical activities of aviation medicine. 
The results of the flying personnel's examinations were available from the terminals installed in the offices of MIAM Commandant and CMAMC Chairman. Access to information was provided based on the conversational software on the basis of an index or name given from the terminal (if it concerned a single person) or on the basis of values of parameters defining a group of persons. It was possible to immediately make a list selected from among several dozen prepared beforehand. The personal data of individual flying personnel members recorded in these systems were available in other systems through the use of a unique personal index.

\section{SPECIALISED SYSTEMS}

The first of the developed specialist systems included the results physical fitness tests of the military flying personnel conducted in the Military Training and Fitness Centers (MTFC). It was used, among other things, to assess physical fitness, set standards and refer pilots to MTFC. Data in this system were entered periodically in the IT Department after receiving source documents from MTFC. These consisted of the results of physical fitness tests and the assessment of physical fitness. In the course of information processing, the system used information collected in systems supporting certification activity.

A large number of those examined in CMAMC specialist surgeries and a large amount of medical information, as well as a need for in-depth analysis of data, evaluation of treatment effectiveness and quick access to selected information, created premises for commencing work on computerization of three surgeries: cardiology, endoscopy and dentistry.

The cardiology surgery support system collected, processed and made available the results of cardiovascular examinations in pilots observed for: cardiac rhythm and conduction disorders, suspicion of coronary artery disease. The system recorded data from history, physical examination, resting and exercise ECG examination, 24-hour ECG monitoring and other specialist cardiovascular examinations (echocardiography), effects of pharmacological treatment.

The endoscopy surgery support system collected, processed and made available the results of stomach and duodenum examinations in patients with or at risk of ulcer disease. The system recorded data from the history, results of endoscopic examinations, method and results of pharmacological treatment.
The system supporting the dental office collected, processed and made available data on the condition of teeth and periodontium for all military flying personnel. This system enabled individual and group analysis of the dynamics of changes in the dental condition and provided guidelines for taking preventive measures. Ultimately, the first two systems were to be consultation and review systems.

\section{TRACING SYSTEMS}

The first of the implemented systems was used to assess exercise capacity in dynamic conditions on a moving raceway or cycloergometer. A whole range of physiological indicators were recorded there. It was possible to conduct physical training in accordance with a previously developed program with simultaneous control of the frequency of heart contractions, eliminating the possibility of overloading the cardiovascular system. The first version of the system was developed on the basis of a mini-computer MERA-400, and the next one on the basis of a microprocessor technology.

Subsequent very important systems supported examinations in aeromedical simulators: lowpressure chambers and a High-G centrifuge. Different physiological parameters were measured and analyzed during the examination. In particular, the systems did not allow for critical situations in the test organisms. These systems were based on IBM PC microcomputers.

\section{MEASUREMENT AND INFORMATION SYSTEMS}

The first example of systems in this class is the system for testing the equilibrium organ using posturography method. The initial version of the system was developed on the basis of the minicomputer MERA-400. Later a version based on IBM PC was created.

Another example was the system for the assessment of physical fitness of the pilot's system in variable flight conditions, consisting of a measurement part and an evaluation system.

The system supporting neurological diagnostics and supervision was also developed using modern topographic methods. The system was implemented on the basis of IBM PC microcomputer and put into service. The use of the system allowed for the assessment of brain function, measured by its bioelectric activity. The system allowed not only to obtain data on the momentary state of the patient, but also to analyze and record 


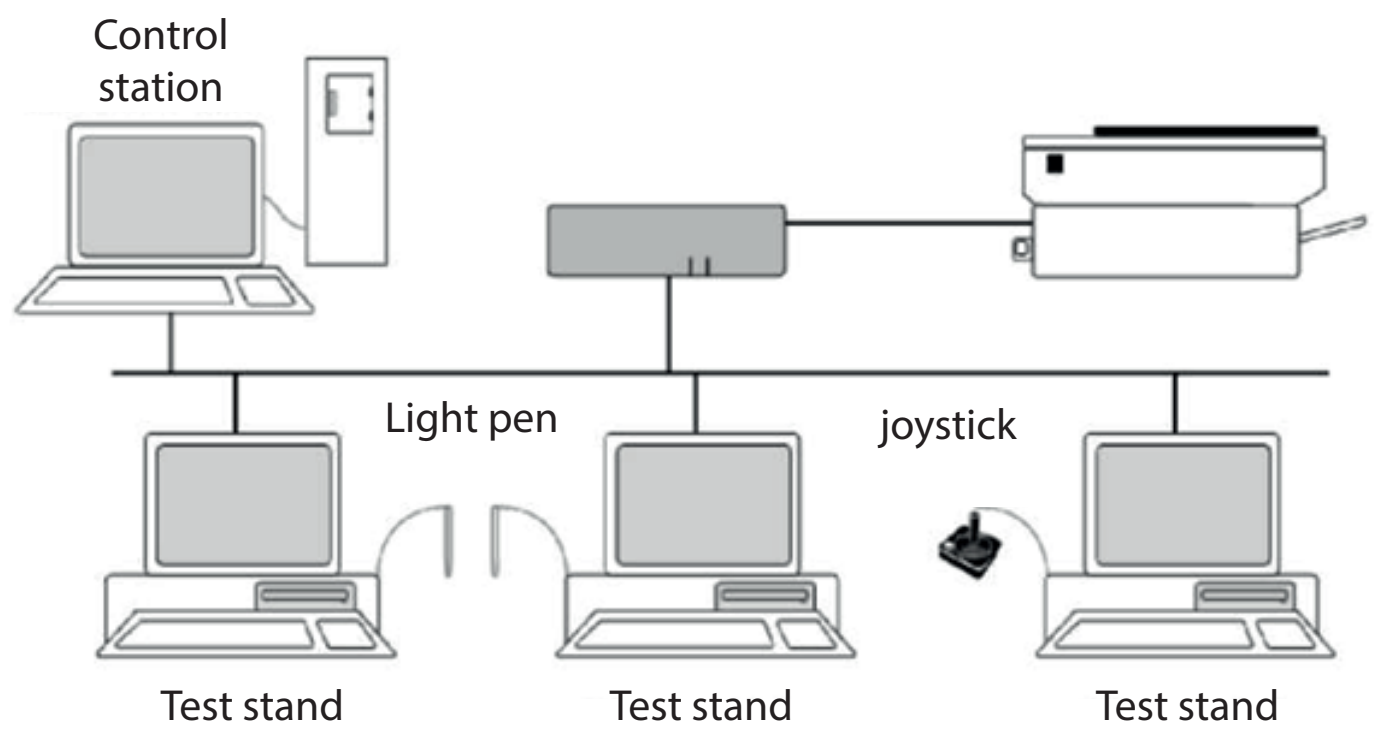

Fig. 2. Hardware base for group psychological examination system.

changes in his/her condition over long periods of time. The information in the system was organized in the form of a hierarchical database, which allowed easy access to all the results and allowed to perform various analyses. Other systems concerned chronophysiology and included:

- use of the frequency of heart contractions to assess the physical and mental strain on the body, including shift work (day and night), and the load on the body during real flight and simulation tasks,

- analysis of ECG record morphology in stressful situations.

The basis for the analysis was the record of 24-hour ECG signal by means of MEDILOG system, directly connected to the IBM PC type computer.

$\mathrm{PC} / \mathrm{XT}$ computers with color monitors, light pens and joysticks. Another system developed was an integrated system of psychophysiological tests, designed for routine group psychological tests and research work in the field of clinical psychology ${ }^{2}$. It was based on the D-Link network with a PC/AT computer as a control station, where the scope and sequence of research was planned. Several test stands were based on PC/XT computers with color monitors, light pens and joysticks. $\mathrm{PC} / \mathrm{XT}$ computers with color monitors, light pens and joysticks.

Several psychological tests were implemented in the system (from questionnaires to apparatus tests - with time parameters measurement), including, among others:

2 The concept of the system was developed by prof. Jan Terelak and the author of this article.
1) Numerical tables. Test of perceptual efficiency in terms of function: perceptual speed, divisibility of attention, operating memory, as well as visual and motor coordination.

2) Bourdon test. Attention divisibility and concentration, visual tracking speed test.

3) Kraepelin arithmetic test. Work pace and mental capacity as well as fatigue in monotonous conditions test.

4) Simple Response Time. Measurement of the simple reaction time (SRT), i.e. the time needed to start the motor response act when the stimulus is detected.

5) Choice Reaction Time. The Choice Reaction Time (CRT) is the time it takes to perceive a stimulus, identify it and decide on the choice of an appropriate motor response to the stimulus.

6) Cross Test - Sight and Movement Coordination. The test of general psychomotor performance covering such functions as: visual and motor coordination, perceptiveness, concentration and attention shifting, as well as fatigue resistance.

7) Piórkowski's Test - of sight and Movement Coordination. Measurement of the speed of a psychomotor response at an imposed or free rate, in terms of perceptiveness and divisibility of attention, and in terms of visual and motor coordination.

8) Perception - Spatial Relations Test. Examining spatial imagination and reasoning on spatial forms.

The system had the following functions:

- ordering tests - the function was used to assign to a test stand a test or a set of tests, to determine the parameters for the test (e.g. test 
duration, work rate) and to enter or read from the personal database the personal data of the person undergoing tests,

- review of results - the possibility to run another test on individual stands after the operator has viewed the results of the current test or without doing so was created,

- review of tasks - preview of the status of tests at individual stands,

- database review - a review of the results of previous tests with the possibility of printing them out,

- printout manager - printing the results of completed tests on an ongoing basis without "disrupting" ongoing tests, i.e. in multi-tasking and multi-use mode,

- generation of standards - generating new standards on the basis of the collected test results. To this end, the system required at least 100 test results. This function could also been used to print out the entered or calculated standards. Newly calculated standards became mandatory after the acceptance of the system operator,

- creating a set /battery/ of tests - creation of specific test suites.

An important function of the system was to measure selected physiological indicators (pulse, breath, skin resistance), which were correlated with the results of psychological tests. This enabled research to be carried out into, among other things, stress factors.

\section{HOSPITAL SYSTEM}

The computerization of MIAM Hospital started in 1992. All the software for the system was developed by the MIAM Department of Computer Science in Fox-Pro database language. This made it possible to make the necessary changes and corrections on an ongoing basis and to extend the functions in direct contact with the users. It also created the possibility of direct operation of the software being developed under the Unix operating system.

The system was designed with the following objectives in mind:

- enabling direct management of diagnostic and therapeutic processes, ensuring, among other things, shortening the time of patients' stay in hospital, as a result of the acceleration of information flow and reduction of the impact of bottlenecks, occurring, among others, in specialist diagnostic laboratories. An important element was the attempt to automate the treatment costs assessment and to automate reporting,

- shorten the time spent by doctors and nurses on preparing medical records (each piece of information is entered only once with the possibility of its repeated use) with simultaneous forcing of order, regularity and unification in keeping medical records and reducing their quantity and fragmentation,

- implement automatic updating of the dispersed database on the course of diagnostic and therapeutic processes and their effectiveness. Elements of this database were to be used directly in scientific and research works conducted at MIAM.

The hardware base of the hospital system was the Novell network of IBM PCs with a PC 386 server. The installation of the network required the laying of transmission and power supply cables, the total length of which amounted to almost $2 \mathrm{~km}$.

Workstations were installed, or the possibility of installing them was ensured, in all hospital units: Admission Unit, Nurse Stations, Medical Rooms, Diagnostic Labs, Clinical Laboratories, Radiology Department, Hospital Pharmacy and Medical Statistics Department.

4 layers were distinguished in the system: "Patients Flow", "Patient Care", "Diagnostics" and "Therapy". They included modules such as "Clinic" or "Clinical Laboratory", at selected workstations, e.g. within the "Clinic" module: "Nurse Station" and "Clinic Physician Room".

Since 1 January 1993, the "Patients Flow" layer has been operated at the MIAM Hospital 24 hours a day, supplied with information from the workstations of the "Admission Unit" and "Nurse Station" in all 5 clinics, providing data to the "Medical Statistics Department" station. It should be mentioned that prior to the implementation of the "Patients Flow" module, each future user received 8-hour training, both in the basics of computer use and in the rules of using the developed software. The software was then put into trial operation.

\section{"Clinic Physician Room" workstation}

The software developed for this station enabling:

- history taking (review of systems) and physical examination,

- ordering pharmacological treatment (data were transferred automatically to the appropriate Nurse Station),

- ordering tests to the Clinical Laboratory and the Radiology Department, 
- automatic recording of the results of tests performed in the Clinical Laboratory and Radiology Department,

- printing of necessary documents (e.g. "Medical Case Record", "Discharge Summary", prescriptions, sick leave forms),

- making specific compilations, for example in the form of contingency tables for a flexibly defined set of patients.

\section{"Clinical Laboratory" module}

It enabled computer-aided:

- registration of orders for outpatient tests,

- registration of orders for hospital tests,

- registration and segregation of samples,

manual entering of test results to the local database,

- automatic entering of the results of tests carried out with the use of analyzers to the local database,

- formal and substantive verification of test results,

- transmission of the results of the clinic's tests,

- printing of the results of outpatient tests and specific results of hospital tests,

- carrying out compilations and statistical calculations.

Notable should be in-house development of software and hardware solutions, enabling the results of tests carried out with the help of the SERONO-BAKE 9000 hematology analyzer and the CEBA-CORNING biochemical analyzer to be automatically entered in the local database.

\section{“Radiology Department" Module}

The described module was used on 4 workstations, installed in the Department Reception, Ultrasonography Laboratory, X-ray Room, X-ray Consulting Room and enabled to perform the following functions:

- registration of orders for outpatient tests,

- planning of tests dates,

- registration of tests execution,

- describing the results of tests,

- printing of registers,

- carrying out quantitative statements.

\section{Automated statistical analysis package}

A conversational and automated CMS statistical inference package was developed in two versions: for IBM PC microcomputer and for SM-4 minicomputer. The package consisted of a number of related programs in the object form and a library of subprograms.
The package made it possible for researchers to carry out calculations directly by automatically selecting the right statistical methods on the basis of automatically verified conditions ${ }^{3}$.

So far, the operation of the developed system has shown its relatively high versatility. It was an effective tool in scientific and research work, significantly shortening the time and increasing the accuracy of statistical analysis of results of medical examinations and experiments.

\section{RECAPITULATION}

The IT support for MIAM activities, developed until 1995, confirmed the usefulness of IT methods and means, as well as identified the growing demand for their use.

It should be noted that the use of IT improved the diagnosis and treatment of flying personnel, enabled comprehensive data analysis, shortened the time of access to information and enabled proper data storage and security. It was not without significance that the reporting and recording units were relieved of the burden of time-consuming and laborious compilations and reporting. It was planned to extend storage in the examination results sets instead of aggregated specialist assessments and to adapt source documents to the requirements imposed by computerization.

As part of the further development of IT, it was planned to:

- provide computer support for the most active certification and medical processes,

- expand tests support systems,

- establish a uniform certification and diagnostic activities support system,

- ensure direct, continuous and natural access to all registered certification and medical information.

Comprehensive work was also planned aimed at developing mathematical models of the processes of changes in the health condition of flying personnel and the correctness and effectiveness of the conducted certification, diagnostic and therapeutic activities. A significant problem awaiting a comprehensive solution was forecasting the drop out rate of pilots.

3 For developing a conversational CMS package, the author of the article and his team were awarded the Third Degree Team Prize in military medicine on 12 October 1985 by the Minister of National Defense. 


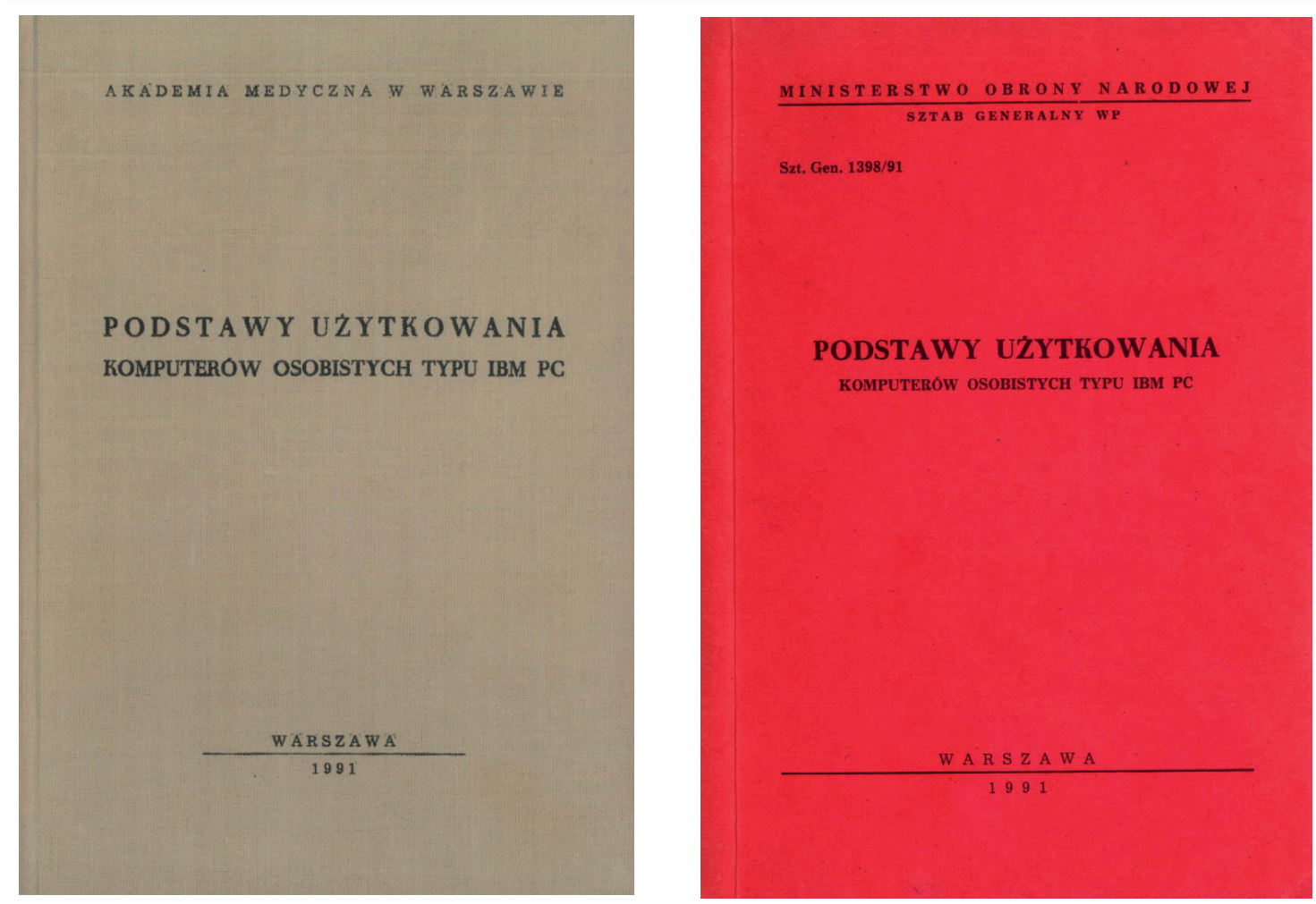

Fig. 3. Textbooks published under the editorship of the author of the article.

\section{Calculation of the results of admission examinations to the Medical Academies}

Since 1986, under a contract awarded by the Minister of Health, WIML's Department of Computer Science was calculating the results of admission examinations to all 12 Medical Academies.

This was a high-risk undertaking due to the need to ensure the possibility of loading the answers written in pencil on the response cards there were no scanners at that time. This was done with the use of a perforated card reader after the installation of additional prisms and the modification of the reader electronics.

The developed technology was in use for several years and was appreciated in a letter dated 18 July 1990 by the Director of the Department of the Ministry of Health and Social Welfare, dr. n. med. Rafał Niżankowski, which included, among others, such statements: "reliable technical and organizational preparation of the process of computer calculation of test results of admission examinations to medical academies" and "an extremely responsible undertaking was carried out in an efficient and timely manner".

\section{Developing a IBM PC User's Guide}

The high level of professional knowledge and skills of the employees of the MIAM Department of Computer Science enabled, at the initiative of the author of this article and with his participa- tion and editing, the development and publication in 1991 of the first Polish textbook "Podstawy użytkowania komputerów osobistych typu IBM PC" (Basics of using IBM PCs).

The textbook was first published at the Medical Academy in Warsaw, and then by the General Staff of the Polish Armed Forces - signature: Szt. Gen.1398/9144.

\section{Commemoration of Home Army soldiers - MIAM employees}

On 6 April 2016 during a ceremonial meeting of the Scientific Council held at the Military Institute of Aviation Medicine, soldiers of the Home Army, employees of $\mathrm{MIAM}^{5}$, were honored.

All participants of the ceremony received a specially prepared and published book "Żołnierze Armii Krajowej - pracownicy MIAM" containing 15 biographies. These biographies are also available on the website: http://armiakrajowa.org.pl/tabliczki/198.html.

4 The textbook was recommended for use in the Armed Forces of the Polish Army by the Deputy Chief of the General Staff of the Polish Armed Forces gen. bryg. Henryk Andracki. In February 1992, the authors of the textbook were awarded with diplomas by the 14th General Staff Head, who stated that the textbook has"a high substantive value and a high practical value".

5 http://armiakrajowa.org.pl/452-uroczysto-w-wojskowym-instytucie-medycyny-lotniczej. 


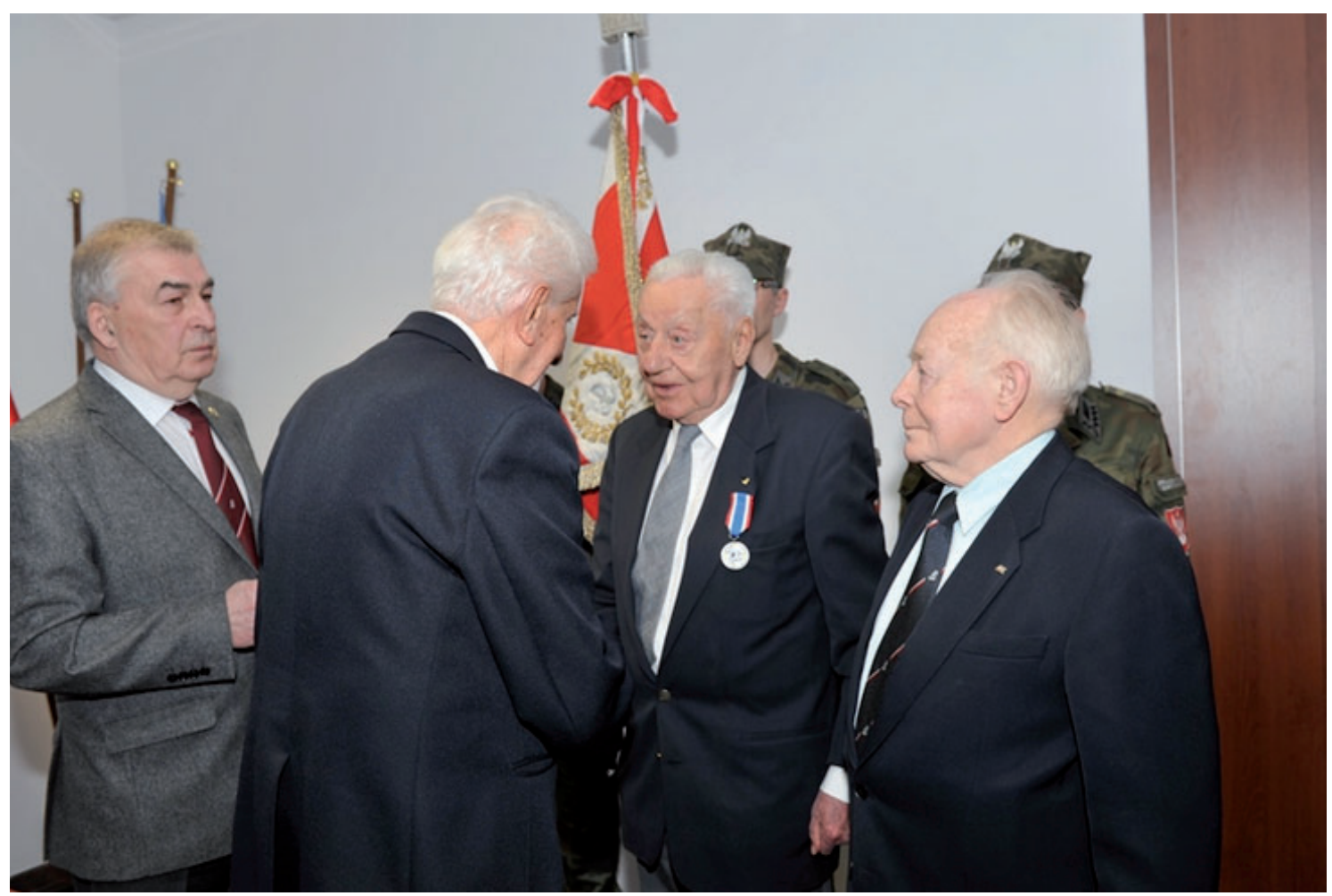

Fig.4. Decorating MIAM employees with "Merit for the World Association of Home Army Soldiers" decorations (from the left: author of the article, prof. Leszek Żukowski, colonel at rest. prof. Eugeniusz Sokołowski and colonel at rest. mgr Stefan Laube).

Professor Leszek Żukowski, President of the World Association of Home Army Soldiers, presented the decorations "For merits to the World Association of Home Army Soldiers" to two living Home Army soldiers - employees of MIAM and to the families of the two deceased soldiers, as well as to the Military Institute of Aviation Medicine.

At the end of the ceremony, a previously handed over plaque with a QR code with the address of the website written down was unveiled by last living Home Army soldiers, former WIML employees - colonel at rest mgr Stefan Laube and colonel at rest. prof. Eugeniusz Sokołowski.

After the plaque was unveiled, the $Q R$ code was scanned and the participants of the ceremony could see the content of the site with biographies on a large screen.

\section{AUTHORS' DECLARATION:}

Study Design: Marek Cieciura; Data Collection: Marek Cieciura; Manuscript Preparation: Marek Cieciura. The Author declares that there is no conflict of interest. 